\title{
EVALUATION OF ECOLOGICAL CIVILIZATION DEVELOPMENT IN THE POST-OLYMPIC TIMES
}

\author{
YANG, P. ${ }^{1}-$ SHENG, X. ${ }^{1 *}-$ ZHAO, $.^{2}-$ ZHU L. $^{3}$ \\ ${ }^{1}$ Management School, Beijing Union University, Beijing 100101, China \\ (e-mail:963450574@qq.com-P.Yang)
}

${ }^{2}$ School of Applied Science and Technology, Beijing Union University, Beijing 100101, China (e-mail:1447502494@qq.com)

${ }^{3}$ College of Business and Public Management, West Chester University, West Chester 19383

$P A, U S A$

(e-mail: xzhu@wcupa.edu)

*Corresponding author

e-mail: shengxiaojuan@buu.edu.cn

(Received $8^{\text {th }}$ Mar 2019; accepted 21 $1^{\text {st }}$ May 2019)

\begin{abstract}
As a major sport event attracting global attention, the Olympic Games reflect the overall national strength, and highlight the international influence and competitiveness of the host country. As the competitive events have a requirement for the environment of the host country, which is a good opportunity to improve the ecological civilization of the host country. Beijing 2008 Olympic Games has played an important role in improving the ecological environment of Beijing. With the approaching of the Winter Olympics in 2022, we have ushered in new opportunities to promote the construction of Beijing's ecological civilization. Taking Beijing's ecological civilization as the research subject, we construct the evaluation index system of the index of ecological civilization, and use the coefficient of variation method to determine the weight of the index. It evaluates Beijing's ecological civilization from five aspects: growth quality, environmental protection, environmental quality, resource utilization and environmental governance. It is concluded that the index of Beijing's ecological civilization is on the rise as a whole. It has a significant impact on the construction of ecological civilization, and the measures taken by the government are ready for the successful hosting of the 2022 Winter Olympic Games.

Keywords: ecological environment, host country, Beijing, evaluation index system, comprehensive national strength
\end{abstract}

\section{Introduction}

The Olympic Games held every four years are the most influential international event in the world; it is of great consequences and will bring far-reaching significance for any hosting country. The 2008 Beijing Olympic Games not only promoted the economic development of various industries (Kang et al., 2017; Ogunyele et al., 2018), but also improved the urban ecological environment. On the occasion of the Olympics Games, Beijing municipal government carried out environmental protection activities such as increasing green areas, reducing emissions and pollution to further promote ecological development (Geisendorf and Klippert, 2017; Khanchoul et al., 2018). A report delivered at the 19th National Congress stated that we must realize that lucid waters and lush mountains are invaluable assets and we should have a strong commitment to socialist ecological civilization and work to develop a new model of modernization with humans developing in harmony with nature. The concept of ecological civilization has continuously penetrated into all aspects of China's social and economic development. To be better prepared for the 2022 Winter Olympics, we should not only maintain steady economic growth, but also 
maintain a good environmental quality (Zhou et al., 2018; Nawaz et al., 2018). As the capital of China, Beijing must play a leading role in the construction of an ecological civilization.

The term building an ecological civilization is proposed concerning China's construction, while foreign research mainly focuses on environmental aspects of resource utilization, environment and sustainable development. International organizations, foreign governments and scholars at home and abroad have constructed a number of sustainable development evaluation index systems from different perspectives. So far, there are four versions namely EPI2008, EPI2010, EPI2012 and EPI2014. Foreign researches on the ecological environment have been relatively complete, providing a good foundation for us. Eco-civilization is a concept with Chinese characteristics, which is of great significance to the sustainable development of China. Since the successful completion of the 2008 Beijing Olympic Games, more attention has been paid to the ecological environment (Shen, 2018). Chinese scholars have provided new strategies for environmental improvement (Fernando, 2016; Arslan et al., 2018) from the perspective of behavioral science. From the perspective of green ecological planning and economy, they have found that new urban planning can promote the construction of resource-based cities (Guan, 2016). Eighteen evaluation indicators were selected from water carrying capacity, land carrying capacity, atmospheric environmental carrying capacity, energy carrying capacity and environmental carrying capacity. An index system of carrying capacity of urban resources and environmentally friendly living in ecological civilization (Zhang et al., 2017; Kumar, 2018) was established. The model method of ecological benefit and trade-off in circular economy practice was also provided, as well as the development of regional ecological industry (Sun et al., 2017). For China's rapid urbanization, Guiyang and Port, as typical eco-civilized cities, provide an ideal laboratory to develop a hybrid model of carbon emissions and energy consumption (Fang et al., 2017; Liang and Wenshun, 2019), and provide policy guidance for the port to promote the construction of ecological civilization from the perspective of PECC ( $\mathrm{Li}$, et al., 2018). Not only should we pay attention to the education of ecological civilization, but also to the regional ecological innovation in China (Yu et al., 2016). Scholars have established a comprehensive evaluation model of ecological civilization education in Colleges and universities (Ping et al., 2018; Suhaili and Samsudin, 2018), and selected 30 provinces. The level of regional ecological innovation was evaluated, and the factors influencing regional ecological innovation in China (Chen et al., 2017; Rajendran and Mohsin, 2018) were obtained.

To sum up, scholars at home and abroad have inherited rich experience and achieved fruitful research results. Because of different research directions, there is no uniform standard for evaluation index. Most of the studies at home and abroad focus on the macro level of environment and city, without considering the impact of major historical events on ecological civilization. Based on this, this paper takes Beijing as the research object, evaluates the development of ecological civilization after the Olympic Games, and predicts the ecological civilization of the Olympic Games in 2022, which is also the starting point and innovation of this paper.

\section{Materials and methods}

\section{Evaluation of research thought of ecological civilization}

Ecological civilization is the inevitable requirement for the harmonious coexistence of man and nature. It is a synthesis of eco-politics, eco-economy, eco-environment, eco-culture 
and eco-system. On the basis of previous studies, this paper draws lessons from the existing index system, relevant policies and the actual situation of Beijing, constructs the evaluation index system of ecological civilization, which can better measure the ecological civilization index of Beijing (Serpe, 2018; Madhav et al., 2018). In order to establish a harmonious development between human and nature, there are five secondary indicators, namely, growth quality, environmental protection, environmental quality, resource utilization and environmental governance. Each secondary indicator has corresponding three-level indicators, totaling 27 three-level indicators. The ecological civilization index is calculated more scientifically from five different aspects. Based on scientific principles and from the practical point of view of the construction of ecological civilization, this paper takes Beijing and 16 regions as the research objects, adopts the time series data of Beijing from 2009 to 2016 and the panel data of air quality of each region, carries out the comprehensive evaluation of ecological civilization, and predicts the ecological civilization index of the 2022 Winter Olympic Games. By comparing the air quality of different regions (Lee, 2016), the regional disparities and shortcomings in the process of ecological civilization construction in Beijing and other regions are analyzed, the main influencing factors of ecological civilization in Beijing are revealed, and the direction of efforts is determined (Lee et al., 2016; Raj and Prabhakaran, 2018), so as to provide a better living environment for the hosting of the Winter Olympic Games.

\section{Construct an evaluation index system and weight determination}

The scientific indicator system is crucial for the objective evaluation of ecological civilization. The quality of indicators directly affects the scientific nature and accuracy of results of ecological civilization evaluation. Based on the scientific nature of indicators (Marinelli, 2018), the availability of data, the comparability of regional data, the measurability of results, and the principles of predictability, an ecological civilization indicator system is constructed. It is necessary to consider the new elements arising from the 2008 Olympic Games. In the light of the resource-constrained objectives set out in the 12th Five-Year Plan Outline for National Economic and Social Development and the 13th Five-Year Plan Outline for National Economic and Social Development (Oglu Nasirov, 2018), the 19th National Congress put forward the socialist ecological concept. The General Office of the State Council issued the Evaluation and Evaluation System for the Objectives of Ecological Civilization Construction and Green Hair. On the basis of the exhibition index system and the "Three-year Action Plan for Winning the Blue Sky and Defending the War" issued by the State Council, as well as the existing research results on ecological civilization at home and abroad, the index system of ecological civilization in Beijing is constructed.

According to the connotation of ecological civilization and the design principle of the index system, the three-level index system is constructed, and the comprehensive evaluation index system is progressive step by step (Sun et al., 2016). The whole index system is divided into three levels, the first level is the target level and the general goal; the second level is the factor level, which is the factor influencing the overall goal. The ecological civilization index of the target level is divided into five elements, namely, growth quality, ecological protection, air quality, resource utilization and environmental governance; the third level is the index level, which is composed of 27 indicators. In the total index system, there are 11 absolute indexes and 16 relative indexes. Among them, there are 20 positive indicators and 5 negative indicators. This paper takes Beijing as the research object., the evaluation data comes from Beijing Statistical Yearbook 2009- 
2016, Statistical Yearbook 2009-2016 of Beijing Municipal Environmental Protection Bureau, Statistical Yearbook 2009-2016 of Beijing Water Affairs Bureau, Annual Report on Ecological Civilization of Beijing Environmental Protection Bureau in 20092016, Statistical Yearbook of Beijing Municipal Bureau of Landscape Architecture 2009-2016 and other relevant statistical yearbooks (Song et al., 2016). Because some data are not available, the method of interpolation is used to calculate the missing data.

The determination of index weight is a key factor in the evaluation of ecological civilization index (Table 1). The weight of the index affects the scientific nature of the evaluation results. According to the nature of the evaluation indicators (Zhang et al., 2016), the evaluation indicators are divided into two categories: positive indicators and negative indicators. The positive indicator is the indicator that the bigger the value, the better, and the negative index is just the opposite. Considering the characteristics of ecological civilization, research needs and actual situation, this paper will use the variable coefficient in the objective weighting method to determine the weight of each index. The weights of each indicator are calculated as shown in Table 1.

Table 1. Weight of each indicator in the indicator system

\begin{tabular}{|c|c|c|c|c|c|}
\hline $\begin{array}{c}\text { Grade } 1 \\
\text { indicator }\end{array}$ & $\begin{array}{c}\text { Grade } 2 \\
\text { indicators }\end{array}$ & Weight & Grade 3 indicators & Nature & Weight \\
\hline \multirow{27}{*}{ ECI } & \multirow{6}{*}{ Growth quality } & \multirow{6}{*}{0.220892487} & GDP per capita (yuan/person) & Positive & 0.031709382 \\
\hline & & & Urban per capita disposable income (yuan) & Positive & 0.038115002 \\
\hline & & & Rural per capita disposable income (yuan) & Positive & 0.032653215 \\
\hline & & & $\begin{array}{c}\text { Contribution of tertiary industry to regional GDP } \\
\text { growth }(\%)\end{array}$ & Positive & 0.039223131 \\
\hline & & & R\&D fund investment $(\%)$ & Positive & 0.019192412 \\
\hline & & & Urbanization rate $(\%)$ & Positive & 0.019983622 \\
\hline & \multirow{6}{*}{$\begin{array}{l}\text { Ecological } \\
\text { protection }\end{array}$} & \multirow{6}{*}{0.131205615} & Forest coverage rate $(\%)$ & Positive & 0.03765499 \\
\hline & & & Living wood growing stock $\left(10,000 \mathrm{~m}^{3}\right)$ & Positive & 0.035318786 \\
\hline & & & Proportion of nature reserve in urban area $(\%)$ & Positive & 0.043285846 \\
\hline & & & Urban green coverage ratio $(\%)$ & Positive & 0.032408979 \\
\hline & & & Forest coverage rate $(\%)$ & Positive & 0.035415529 \\
\hline & & & Per capita park green space ( $\mathrm{m}^{2} /$ person $)$ & Positive & 0.025207522 \\
\hline & \multirow{6}{*}{$\begin{array}{l}\text { Environment } \\
\text { quality }\end{array}$} & \multirow{6}{*}{0.212767028} & Chemical oxygen demand (10,000 tons) & Negative & 0.044148014 \\
\hline & & & Ammonia nitrogen emissions $(10,000$ tons $)$ & Negative & 0.058856794 \\
\hline & & & Sulfur dioxide emissions (10,000 tons) & Negative & 0.039333396 \\
\hline & & & Soot emissions $(10,000$ tons $)$ & Negative & 0.037713962 \\
\hline & & & Mean noise of regional environment $(\%)$ & Negative & 0.035089344 \\
\hline & & & Mean noise of trunk roads $(\%)$ & Negative & 0.02527412 \\
\hline & \multirow{4}{*}{$\begin{array}{l}\text { Resource } \\
\text { utilization }\end{array}$} & \multirow{4}{*}{0.22308159} & $\begin{array}{l}\text { Comprehensive utilization rate of general industrial } \\
\text { solid wastes }(\%)\end{array}$ & Positive & 0.03247559 \\
\hline & & & Comprehensive utilization rate of hazardous waste $(\%)$ & Positive & 0.033620128 \\
\hline & & & Per capita water resources ( 100 million $\mathrm{m}^{3} /$ person $)$ & Positive & 0.036348532 \\
\hline & & & Per capita water consumption $\left(10,000 \mathrm{~m}^{3} /\right.$ person $)$ & Positive & 0.058662852 \\
\hline & \multirow{5}{*}{$\begin{array}{c}\text { Environmental } \\
\text { governance }\end{array}$} & \multirow{5}{*}{0.21205328} & Sewage treatment rate $(\%)$ & Positive & 0.038919427 \\
\hline & & & Harmless treatment rate of domestic garbage & Positive & 0.023913285 \\
\hline & & & $\begin{array}{c}\text { Proportion of environmental pollution prevention } \\
\text { investment in GDP }(\%)\end{array}$ & Positive & 0.054794877 \\
\hline & & & $\begin{array}{c}\text { Proportion of pollution reduction investment in GDP } \\
(\%)\end{array}$ & Positive & 0.041328738 \\
\hline & & & $\begin{array}{l}\text { Proportion of natural ecological protection investment } \\
\text { in GDP }(\%)\end{array}$ & Positive & 0.049352524 \\
\hline
\end{tabular}


As can be seen from Table 1, Beijing's ecological civilization is evaluated from these five aspects (Glenys, 2017). Among grade 2 indicators, growth quality, environmental quality and resource utilization account have a large weight ratio, which is due to reasonable and effective policies implemented by government. The weight of ecological protection is relatively small. It is because the areas of Beijing, nature reserves and forests will not have major changes in years to come, and the amount of change is too small to adjust (Sun, 2018). The Grade 3 indicators of chemical oxygen demand, ammonia nitrogen emissions, sulfur dioxide emissions, the proportion of nature reserves in urban areas, urban green coverage, and proportion of natural ecological protection investment in GDP have a large weight. In the construction of ecological civilization, we should pay attention to the indicators with greater weight and make an improvement from these aspects.

\section{Determination of ECI}

ECI of Beijing and the secondary indicators are calculated by multiplying weight of each indicator by the standardized value. Obviously, the greater the value of the ecological civilization index, the higher the level of ecological civilization, and vice versa. The overall ecological civilization index of Beijing is obtained, which is shown (Table 2).

Table 2. Beijing's ecological civilization index

\begin{tabular}{c|c|c|c|c|c|c}
\hline Year & $\begin{array}{c}\text { Growth } \\
\text { quality }\end{array}$ & $\begin{array}{c}\text { Ecological } \\
\text { protection }\end{array}$ & $\begin{array}{c}\text { Environmental } \\
\text { quality }\end{array}$ & $\begin{array}{c}\text { Resource } \\
\text { utilization }\end{array}$ & $\begin{array}{c}\text { Environmental } \\
\text { governance }\end{array}$ & ECI \\
\hline 2009 & 0.03922313 & 0.02045288 & 0.08077432 & 0.00000000 & 0.09824335 & 0.23869369 \\
2010 & 0.07110915 & 0.04160665 & 0.07450494 & 0.00280862 & 0.03632017 & 0.22634952 \\
2011 & 0.07561496 & 0.04427208 & 0.04787827 & 0.00682093 & 0.03983102 & 0.21441726 \\
2012 & 0.08672186 & 0.07112219 & 0.05467986 & 0.01083324 & 0.04797150 & 0.27132865 \\
2013 & 0.09715975 & 0.10403975 & 0.07935489 & 0.01725294 & 0.09678202 & 0.39458935 \\
2014 & 0.10784921 & 0.17770485 & 0.10218744 & 0.02327141 & 0.09116103 & 0.50217394 \\
2015 & 0.13754789 & 0.19842073 & 0.13413917 & 0.03049357 & 0.10792734 & 0.60852870 \\
2016 & 0.13818652 & 0.19448334 & 0.19970982 & 0.03891943 & 0.11762759 & 0.68892669 \\
\hline
\end{tabular}

\section{Results}

(1) The ECI shows a trend of decreasing first and then rising (Fig. 1).

The ecological index from 2009 to 2011 has slightly decreased. The main reason is that the implementation measures lag behind; as hosting the Olympic Games require financial expenditures in all aspects, many factories were put into production after the Olympic Games to increase positive growth in a timely manner, which emitted a large amount of pollutants, resulting in a decline in the ecological index (Zhang, 2017).

The ECI continued to grow from 2012 to 2016. The main reason is that 2012 is the most crucial year for the implementation of the 12th Five-Year Plan for the prevention and control of dangerous pollutants and solid pollutants. Beijing has fully implemented the environmental management system for solid wastes, actively explored the management model of hazardous wastes from social sources, and fully safeguarded the environmental safety of the capital. Secondly, the number of nature reserves has 
increased, resource utilization has become more rationalized, and the government has invested a large amount of money to manage the environment.

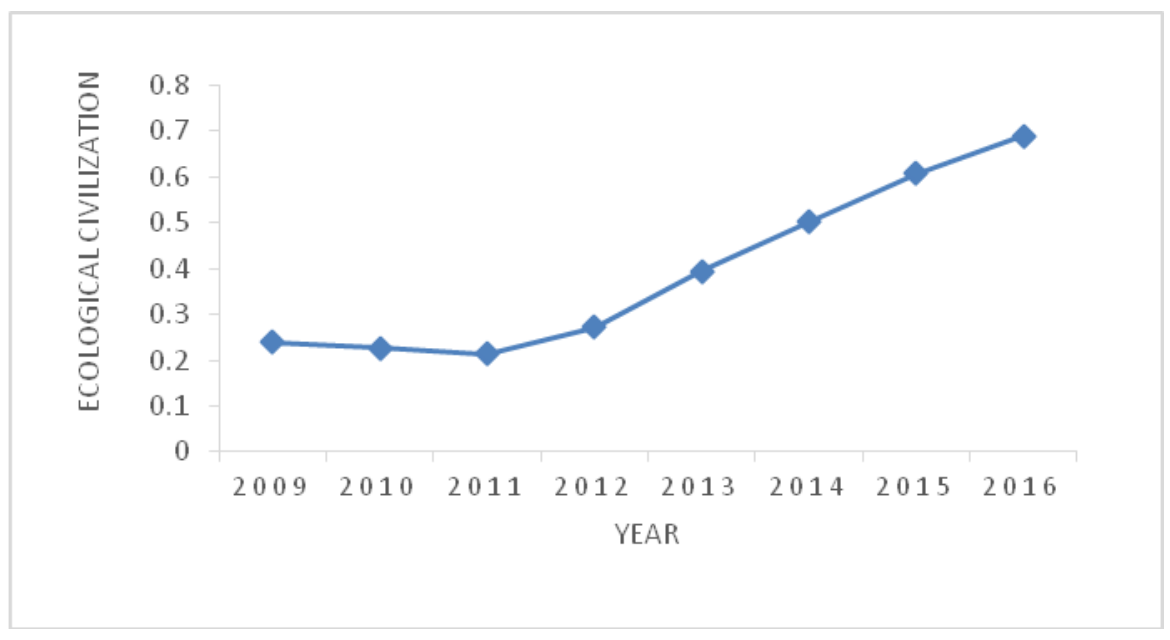

Figure 1. ECI of Beijing after 2008 Olympic Games

(2) The growth quality index first grew at a faster rate, then increased slowly, and finally tended to be stable (Fig. 2).

Beijing's growth quality index is growing steadily. The main reason is that Beijing has actively expanded domestic demand and deepened supply-side structural reforms for the past eight years. The overall economy is stable and positive. Secondly, as a capital city, Beijing is a place that many people yearn for, and a large number of people swarmed into Beijing. In order to solve the employment problem, Beijing government has continued to promote the adjustment of industrial structure, accelerated the construction of science and technology innovation centers, and increased the disposable income of residents. Science and technology innovation has become a new engine of economic growth, and Beijing's investment in testing and research and development has been increasing. As a result, the Beijing's quality growth index is growing steadily (Zhang, 2018).

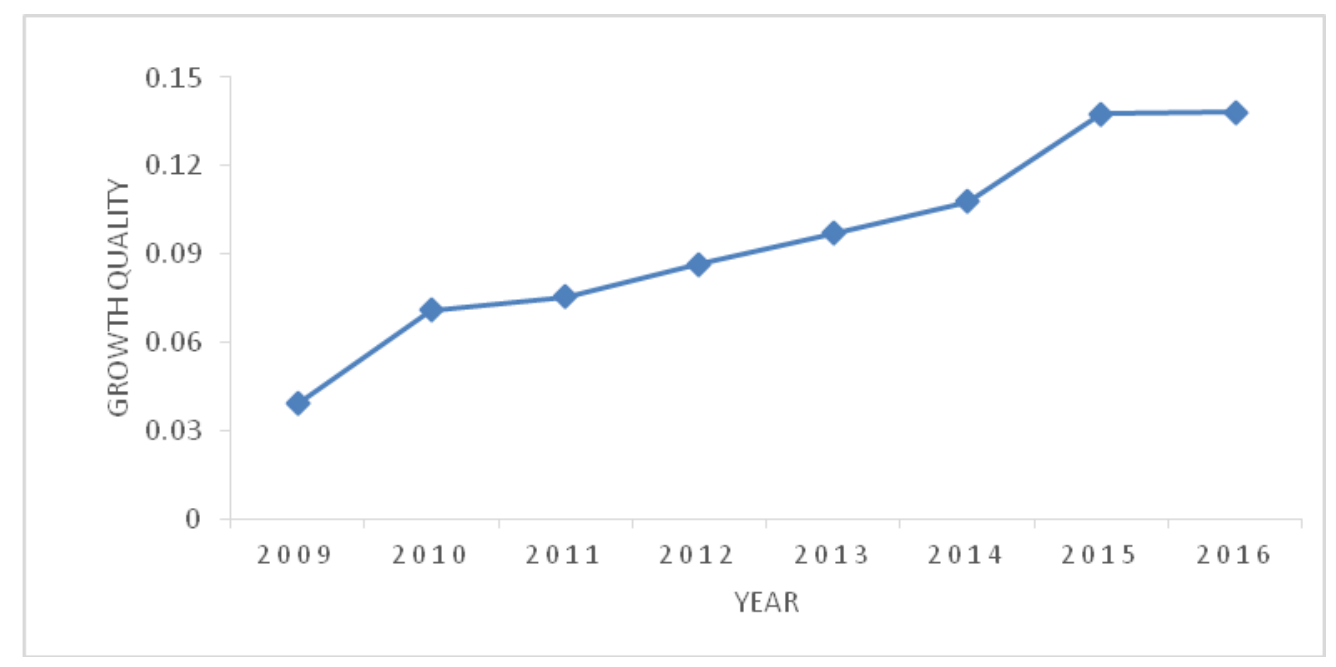

Figure 2. Growth quality index of Beijing after 2008 Olympic Games 
(3) The ecological protection index is growing steadily (Fig. 3).

In 2009-2015, the ecological protection index grew steadily, and it did not change too much in 2016. It was mainly because that the stationarity of Beijing area, forest coverage rate and the proportion of nature reserves in urban areas increased. Furthermore, Beijing government implemented construction projects of nature reserves protection, developed biodiversity protection action plans; and finally, urban greening coverage has been increasing thanks to the construction of national environmental protection model urban areas, ecological zones, and ecological civilization pilot areas.

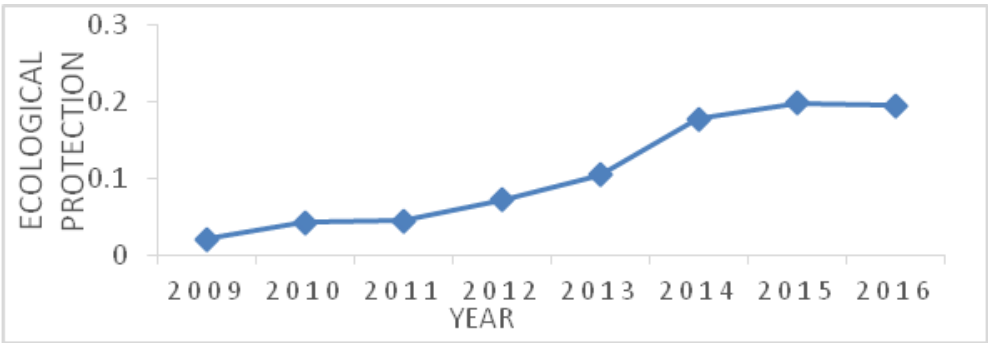

Figure 3. Ecological protection index of Beijing after 2008 Olympic Games

(4) The environmental quality index declined firstly and then rose (Fig. 4).

The environmental quality of Beijing continued to decline during 2009-2011, which was mainly due to construction of a large amount of infrastructure and the investment of a large amount of funds. Besides, the shutdown of a few heavy industries led to a decline in the economic level. In the post-Olympic period, in order to make the economy grow as before, the manufacturing industry resumed production and emitted a large amount of pollutants.

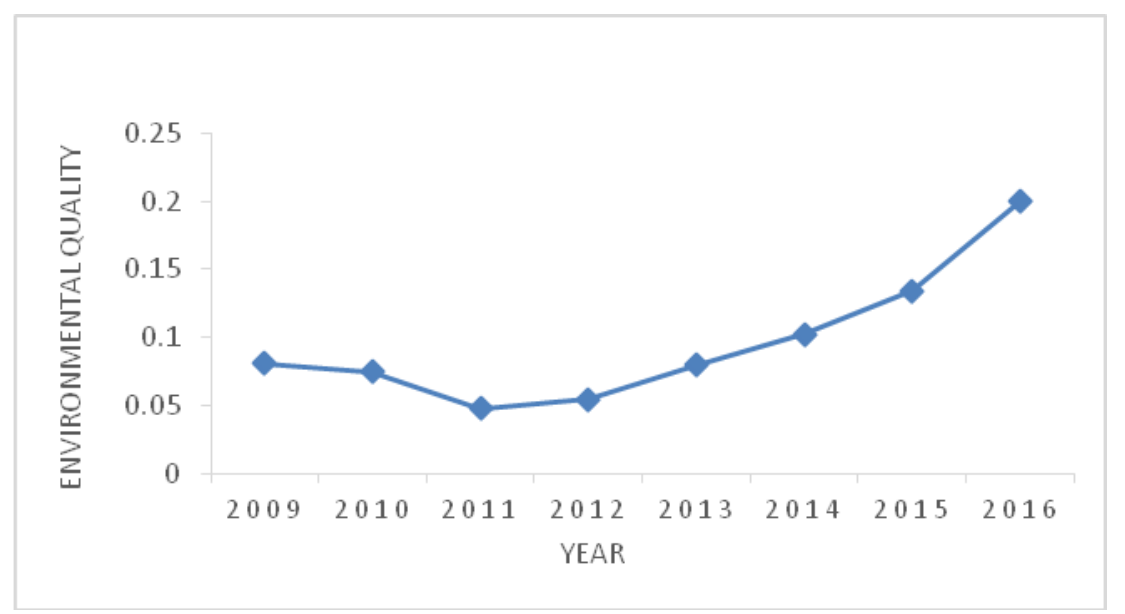

Figure 4. Environmental quality index of Beijing after 2008 Olympic Games

The environmental quality began to increase year by year during 2012-2016. The main reason is that the Environmental Protection Agency has significantly enhanced the prevention and control of atmospheric pollution, pollution reduction and air pollution prevention and control (Feng et al., 2018); secondly, pollution reduction efforts 
continued to be maintained, and air cleaning activities were carried out; finally, unified management was implemented on heavy air pollution (Hao et al., 2019).

(5) Resource utilization index continued to increase (Fig. 5).

The resource utilization index has increased year by year during 2009-2016. Firstly, it was because the solid waste environmental management system was fully implemented and industrial pollution prevention strategies and means were optimized from multiple angles. Secondly, solid waste supervision was strengthened to promote industrial pollution reduction, and the utilization rate of industrial solid waste has increased. Finally, the process will be improved if the pollutants were substandard, so the sewage treatment rate continued to increase.

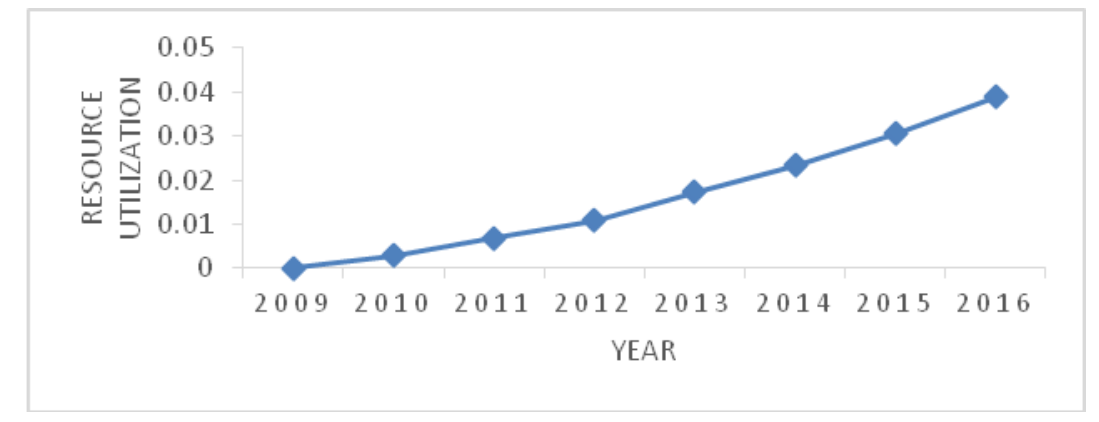

Figure 5. Resource utilization index of Beijing after 2008 Olympic Games

(6) The environmental governance index dropped sharply first, then increased year by year, and finally stabilized (Fig. 6 ).

The environmental management in 2009-2010 dropped drastically. It was mainly due to project expenditure in terms of pollution prevention in 2009 and less investment in similar projects in 2010. Besides, major pollutant emission reduction projects were invested in 2009, and the budget for similar projects in 2010 decreased $(\mathrm{Pu}, 2019)$

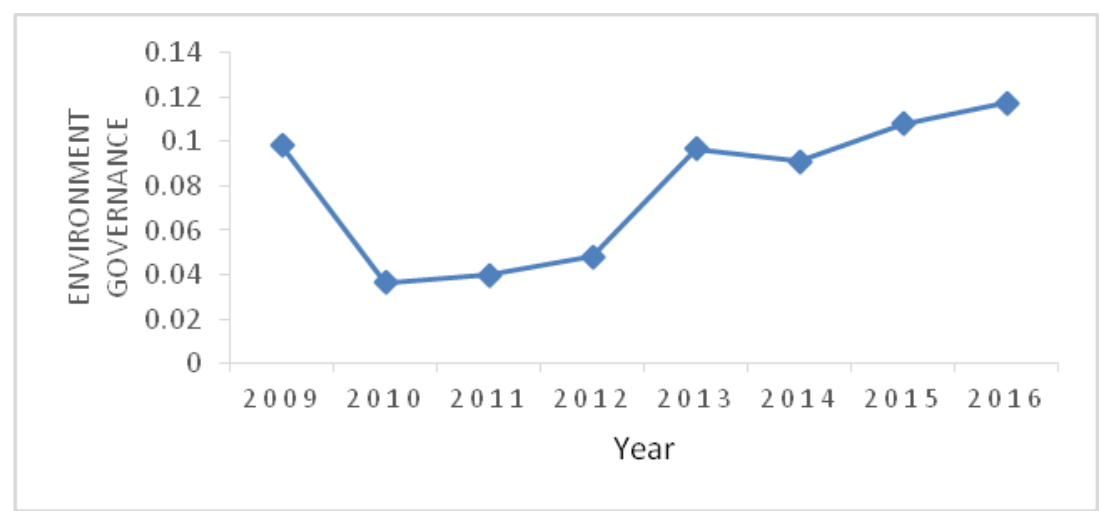

Figure 6. Environmental governance index of Beijing after 2008 Olympic Games

It remained on a slow-growth path in the 2010-2012 and 2013-2016 periods, but achieved rapid growth from 2012 to 2013, which was mainly due to the implementation of the 2013-2016 Clean Air Action Plan. Besides, the unliquidated funds that in the previous year were paid (Wang et al., 2019). 


\section{Discussion}

In this paper, we use the quadratic fit to predict and present a relatively smooth curve. If a fitting is used, a regression straight line will be made, which makes a large error for the result. At this time, a quadratic fitting is required to obtain a quadratic regression equation, making the prediction result more accurate and reliable. The 20092016 data will be used to predict the growth quality, ecological protection, environmental quality, resource utilization, environmental quality and ecological civilization index of the 2022 Winter Olympics. The forecast trend is shown (Fig. 7).

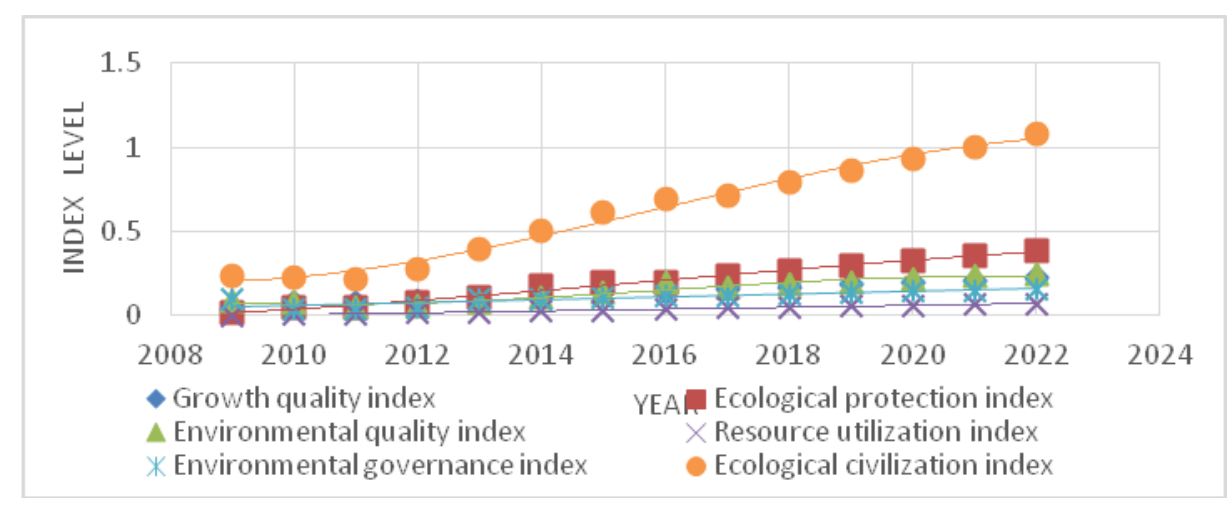

Figure 7. Prediction map of various indicators in Beijing

It can be seen from Figure 7 that the growth quality, ecological protection, environmental quality, resource utilization, and environmental quality index increase in the 2022 Winter Olympics. Therefore, Beijing's ECI has also been increasing year by year. Compared with the ECI of 1.077 in 2020 and 0.717 in 2017, the ECI in the 2022 Winter Olympics increase significantly. Therefore, we believe that the predicted ECI can be achieved if we implement protection policies and improve public awareness of environmental protection.

\section{Conclusions and suggestions}

\section{Conclusions}

(1) Major events such as the Olympic Games have a major impact on the construction of ecological civilization

There are obvious differences in the index of ecological civilization before and after the Olympic Games. The index of ecological civilization has increased significantly after the Olympic Games, which shows that the Olympic Games have a significant impact on the construction of ecological civilization (Chang, 2018).

In order to successfully hold the Olympic Games, the government has adopted effective policies and the index of ecological civilization has increased, which shows that the policy has a great impact on the development of ecological civilization. The economic and ecological development of each region cannot be separated from the regional characteristics and policy impact of each region, which makes the ecological index and air quality index of Beijing and each region improved. 
The Olympic Games is an undertaking that our country has spent a lot of money to accomplish. It is not only to enhance our international status and influence, but also to promote the rapid development of all aspects of our country. The Olympic Games have received the attention of the media from all walks of life, forcing us to issue relevant policy documents, to pay attention to the construction of ecological civilization, and to take the Olympic Games as an important opportunity to promote the coordinated development of ecology and economy.

\section{(2) Get prepared for the 2022 Winter Olympics}

According to the prediction of air quality in Beijing and various regions, the 2022 Winter Olympics will be held in Yanqing District, Beijing, which has laid a good foundation for ecological construction. The ECI and air quality index will reach the ecological environment indicators required for hosting the Olympic Games.

Therefore, before the coming of the Winter Olympic Games in 2022, we must take measures to protect the environment, improve the quality of the environment, and pay attention to the construction of ecological civilization, so as to leave a good impression on the people of the world.

\section{Suggestions}

With the end of the 2008 Summer Olympics, Beijing's ecological civilization has shown a trend of continuous growing of ecological civilization index and the air quality index so far, but there are also some shortcomings. This paper makes the following suggestions for reference.

\section{(1) Enhance protection and improve the effectiveness of environmental policy implementation}

It can be seen from the chart of ECI that the ecological civilization index has dropped significantly after the 2008 Olympic Games. Therefore, in preparing for the 2022 Winter Olympics, we must avoid the occurrence of similar problems, and adopt a longterm mechanism to build an ecological civilization. We cannot rely on temporary management and control, otherwise, it will happen again. Firstly, we should develop effective and targeted measures at regular intervals: environmental pollution control actions; secondly, we will promote the application of new clean energy, prevent and control from the source to reduce tail gas pollution; and finally, develop coordinated development strategy between humans and nature to achieve green development $(\mathrm{Hu}$, 2018).

We should carry out the development strategy of ecological civilization from the following four aspects: in the aspect of eco-economy, vigorously develop tourism and rationally develop local natural resources; in the aspect of ecological environment, we should attach great importance to forestry construction and constantly strengthen the project of benefiting people and increasing green; in the aspect of ecological life, we should save water, reduce waste discharge and improve the rate of waste water treatment; and in the aspect of ecological system. To implement the Party's guidelines and establish a sound ecological environment supervision system. In order to achieve the win-win situation of economic and social development and ecological environment protection, a compound ecological and social system with virtuous circle of economy, society and nature is established. 


\section{(2) Enhance public awareness of ecological protection and enhance environmental responsibility}

We are about to usher in the 2022 Winter Olympics, combined with the socialist ecological concept put forward by the 19th National Congress of CPC, it is a good opportunity for us to strengthen the education of environmental awareness, to put forward the idea of ecological protection, and to achieve it through practice. A series of specific measures can be taken (Chen et al., 2018). For example, the government can conduct environmental education first, so that citizens can establish environmental awareness, form the concept of common development between man and nature in the mind, and secondly, vigorously promote environmental protection knowledge through the influence of the news media. Everyone protects the environment, increases participation in environmental protection issues, and promotes ecological development. Finally, lectures or seminars to protect the environment can be held to raise the awareness of citizen protection. This will enhance the sense of responsibility for environmental protection in the whole society and make the ecological civilization construction of the 2022 Winter Olympics better.

Acknowledgements. This work was supported by Funding of Beijing Philosophical and Social Science Program (No.13JGC123), Funding of Humanities and Social Sciences General Project of the Ministry of Education (No.16YJC630121), Funding of Talents Developing Strategy Plan of Beijing Union University (No. BPHR2018ES02).

\section{REFERENCES}

[1] Arslan, C. H., Sattar, A., Cuong, D. M., Khan, F. U. H., Nasir, A., Bakhat, Z., Ilyas, F. (2018): Study of spatial and temporal variability of arsenic in groundwater due to drain by using GIS. - Earth Sciences Pakistan 2(2): 22-24.

[2] Chang, H., Wang, Z., Li, Y., Chen, G. (2018): Dynamic analysis of a bistable bi-local active memristor and its associated oscillator system. - International Journal of Bifurcation and Chaos 28(08): 1850105.

[3] Chen, C., Xu, J., O'Regan, D., Fu, Z. (2018): Positive solutions for a system of semipositone fractional difference boundary value problems. - Journal of Function Spaces. https://doi.org/10.1155/2018/6835028.

[4] Chen, J., Cheng, J., Dai, S. (2017): Regional eco-innovation in China: an analysis of ecoinnovation levels and influencing factors. - Journal of Cleaner Production 153(1): 1-14.

[5] Fang, K., Dong, L., Ren, J., Zhang, Q., Han, L., Fu, H. (2017): Carbon footprints of urban transition: tracking circular economy promotions in Guiyang, China. - Ecological Modelling 365: 30-44.

[6] Feng, M., Li, P., Sun, S. (2018): Symmetric positive solutions for fourth-order ndimensional m-Laplace systems. - Boundary Value Problems 2018(1): 63.

[7] Fernando, S. (2016): Consumer behavior and sustainable development in china: the role of behavioral sciences in environmental policymaking. - Sustainability 8(9): 897.

[8] Geisendorf, S., Klippert, C. (2017): The effect of green investments in an agent-based climate-economic model. - Environmental Modeling \& Assessment 22(1): 1-21.

[9] Glenys, A. (2017): Labor performance and the stability of administrative personnel contracted in the school of medicine at the University of Zulia. - Argos 34(66).

[10] Guan, H.-L. (2016): Analysis of new urban planning based ecological economics. - Open House International 41(3): 102-106. 
[11] Hao, M., Lu, C., Li, Y. (2019): Simulation experiment study on adhering sand casing well full-waveform characteristics. - Acta Microscopica 28(2).

[12] Hassanpour, M. (2018): Semeiology of Iranian commercial and cultural photomontage posters after the revolution. - Argos 35(71).

[13] Hu, B., Ma, W. X., Xia, T., Zhang, L. (2018): Nonlinear integrable couplings of a generalized super Ablowitz-Kaup-Newell-Segur hierarchy and its super bi-Hamiltonian structures. - Mathematical Methods in the Applied Sciences 41(4): 1565-1577.

[14] Jing, G. (2018): Application of traditional cultural elements in modern urban public art landscape design. - Argos 35(71).

[15] Kang, H., Jung, S. H., Park, D. (2017): Development of an ecological impact assessment model for dam construction. - Landscape and Ecological Engineering 13(1): 15-31.

[16] Khanchoul, K., Saaidia, B., Altschul, R. (2018): Variation in sediment concentration and water discharge during storm events in two catchments, Northeast of Algeria. - Earth Sciences Malaysia 2(2): 01-09.

[17] Kumar, R. (2018): Comparison of instruction scheduling and register allocation for MIPS and HPL -PD architecture for exploitation of instruction level parallelism. - Engineering Heritage Journal 2(2): 04-08.

[18] Lee, B. X., Kjaerulf, F., Turner, S., Cohen, L., Donnelly, P. D., Muggah, R. et al. (2016): Transforming our world: implementing the 2030 agenda through sustainable development goal indicators. - Journal of Public Health Policy 37(1): 13-31.

[19] Lee, M. S. (2016): Global health promotion efforts for achieving the UN 2030 agenda for Sustainable Development, UN 2030. - Korean Journal of Health Education and Promotion 35(4): 1-18.

[20] Li, J., Jiang, B., Lin, N. (2018): A study on the influence mechanism of port environmental carrying capacity. - The Asian Journal of Shipping and Logistics 34(3): 191-197.

[21] Liang, Z., Wenshun, W. (2019): Parametric architectural design based on optimization algorithm. - Engineering Heritage Journal 3(1): 13-17.

[22] Madhav, S., Ahamad, A., Kumar, A., Kushawaha, J., Singh, P., Mishra, P. K. (2018): Geochemical assessment of groundwater quality for its suitability for drinking and irrigation purpose in rural areas of Sant Ravidas Nagar (Bhadohi), Uttar Pradesh. Geology, Ecology, and Landscapes 2(2): 127-136.

[23] Marinelli, M. (2018): How to build a 'beautiful China' in the Anthropocene. The political discourse and the intellectual debate on ecological civilization. - Journal of Chinese Political Science 23(3): 365-386.

[24] Nawaz, A., Arshad, F., Khurshid, F. (2018): Evaluation of low cost environment friendly natural extracts for the purification of drinking water. - Earth Sciences Pakistan 2(1): 2325.

[25] Oglu Nasirov, A. Y. (2018): Importance of silk road in the international trade. - Argos 35(70).

[26] Ogunyele, A. C., Obaje, S. O., Akingboye, A. S. (2018): Lithostructural relationships and petrogenetic affinities of the basement complex rocks around Okpella, Southwestern Nigeria. - Earth Sciences Malaysia 2(1): 29-36.

[27] Ping, R., Liu, X., Liu, J. (2018): Research on construction of indicator system for evaluation of the ecological civilization education in Chinese universities. - Cognitive Systems Research 52: 747-755.

[28] Pu, X., Guo, D., Zhao, Y. (2019): Dual diagnostic method for fracture morphology of thermal coalbed methane reservoir. - Acta Microscopica 28(2).

[29] Raj, N. J., Prabhakaran, A. (2018): Lineaments of Kodaikanal-Palani massif, Southern Granulitic Terrain of Tamil Nadu, India: a study using SRTM DEM and LANDSAT satellite's OLI sensor's FCC. - Geology, Ecology, and Landscapes 2(3): 188-202. 
[30] Rajendran, Y., Mohsin, R. (2018): Emission due to motor gasoline fuel in reciprocating lycoming $\mathrm{O}-320$ engine in comparison to aviation gasoline fuel. - Environment \& Ecosystem Science 2(2): 20-24.

[31] Serpe, C. (2018): The right to education-a key to social-economic development. - Argos 35(68).

[32] Shen, L. (2018): Rural toilet reform: the current situation, problems and countermeasuresbased on the survey of 944 farmers. - Argos 35(68).

[33] Song, M., Guan, Y., Wang, J, Zhao, J. (2016): Evaluation of urban industrial ecological transformation in China. - Clean Technologies \& Environmental Policy 18(8): 1-14.

[34] Suhaili, M. Z., Samsudin, M. D. M. (2018): Utilization of wastewater for corrosion prevention of carbon steel pipe using single chamber microbial fuel cells. - Environment \& Ecosystem Science 2(2): 47-52.

[35] Sun, H. (2018): Analysis on group behavior of college students based on cellular automation. - Argos 35(68).

[36] Sun, L., Li, H., Dong, L., Fang, K., Ren, J., Geng, Y. et al. (2016): Eco-benefits assessment on urban industrial symbiosis based on material flows analysis and emergy evaluation approach: a case of Liuzhou city China. - Resources, Conservation and Recycling 119: 78-88.

[37] Sun, X., Gao, L., Ren, H. (2018): China's progress towards sustainable land development and ecological civilization. - Landscape Ecology 33(10): 1647-1653.

[38] Wang, Q., Zhang, C., Liao, G., Wang, X. (2019): Influence of distribution width on earlyage hydration and setting behaviors of calcium aluminate cement at $20{ }^{\circ} \mathrm{C}$. - Acta Microscopica 28(2).

[39] Yu, Y., Wu, W., Zhang, T., Liu, Y. (2016): Environmental catching-up, eco-innovation, and technological leadership in China's pilot ecological civilization zones. Technological Forecasting \& Social Change 112: 228-236.

[40] Zhang, M., Liu, Y., Wu, J., Wang, T. (2018): Index system of urban resource and environment carrying capacity based on ecological civilization. - Environmental Impact Assessment Review 68: 90-97.

[41] Zhang, W., Yang, J., Fang, Y., Chen, H., Mao, Y., Kumar, M. (2017): Analytical fuzzy approach to biological data analysis. - Saudi Journal of Biological Sciences 24(3): 563573.

[42] Zhang, X., Wang, Y. et al. (2016): Evaluating the trends of China's ecological civilization construction using a novel indicator system. - Journal of Cleaner Production 133: 910-923.

[43] Zhang, X., Wu, J., Liu, L., Wu, Y., Cui, Y. (2018): Convergence analysis of iterative scheme and error estimation of positive solution for a fractional differential equation. Mathematical Modelling and Analysis 23(4): 611-626.

[44] Zhou, X., Liang, X., Du, X., Zhao, J. (2018): Structure based user identification across social networks. - IEEE Transactions on Knowledge and Data Engineering 30(6): 1178119. 